\title{
Thesis
}

\section{Design service-oriented collaborative virtual objects within Internet of things}

\author{
Jordán Pascual Espada \\ Departament of Computer Science, University of Oviedo, Asturias, Spain \\ E-mail: pascualjordan@uniovi.es
}

Keywords: Internet of things, mobile computing, virtual objects, smart environments, context awareness, web applications

On July 18, 2012, Jordán Pascual Espada defended his $\mathrm{PhD}$ thesis at Oviedo University, titled: "Design service-oriented collaborative virtual objects within Internet of things". The research was funded by the Government of the Principality of Asturias (Spain). Jordán Pascual Espada defended his dissertation in a publicly open presentation held in the School of Computer Engineering at Oviedo University, and was able to comment on every question raised by his thesis committee and the audience. The thesis was supervised by his advisors, Juan Manuel Cueva Lovelle and Oscar Sanjuán Martínez, and the rest of his thesis committee, Manuel Pérez Cota, B. Cristina Pelayo García-Bustelo, Rubén González Crespo. The thesis has been read and approved by his thesis committee, receiving the highest rating. All of them were present at the presentation.

\section{Thesis summary}

The main idea behind the "Internet of the things" is quite simple: any properly tagged object will be able to interact or communicate with other objects and systems via Internet, private networks or any other form of communication. Intelligent cell phones, known as Smartphones, are a key element in the development of the Internet of the things. Nowadays, millions of users use their Smartphones to interact with all kinds of physical objects or electronic devices in their environment. In most cases, the interaction process between the Smartphone and the physical objects or devices is managed by a specific software application. Due to these application's features, they often have to be developed specifically as native applications for the target mobile platform. The use of native software applications in the interaction process between Smartphones and physical objects has several unwelcomed consequences, like high costs and development hardships caused by the replication of developments in different mobile platforms $[1,4]$. On the other hand, the actual native application's management implies a series of secondary processes, like the download, installation and configuration. These processes are inappropriate for systems that are based on occasional or precise interaction with physical objects or devices, as secondary actions could take more time than the interaction process itself [2].

The exposed problems have been the motivation for the development of this doctoral thesis, which defines a model applied to the development of mobile applications that base a strong part of their functionality in the interaction with physical objects or nearby electronic devices. The proposed model is not attached to any mobile platform or specific development technology, so it allows the development of valid mobile applications for multiple platforms. Also, the proposal 

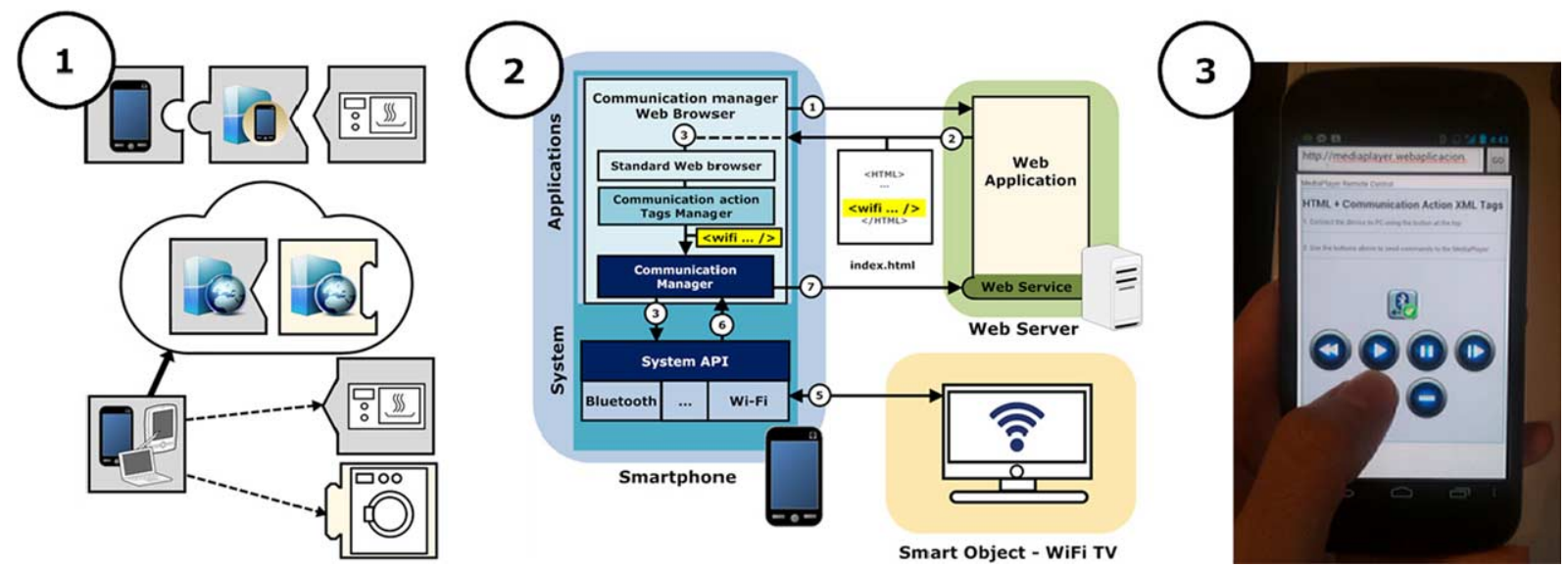

Fig. 1. (1) The solution is based on the use of distributed applications to interact with other devices and smart objects. (2) Communication Manager Web browser - Web Applications Scheme. (3) Image of a prototype web application used to control a media center.

includes optimizations related to the development of this type of applications, such as the abstraction in the management of the hardware elements of the device that allows communication and the capture of context information $[3,4]$. The proposed model dramatically reduces the time used in the secondary processes, making the developed applications optimal for their use in occasional interaction based systems with objects or electric devices. The proposed model is the result of three interaction processes, and each of one has resulted in significant modifications in the architecture and characteristics of the proposal, looking for the best way of reaching these goals [1-4]. The final version of the model is based on a specification that combines with web technologies. The resulting web applications are partially executed in the client device itself, and also in the remote server. This mixed execution method allows web applications to manage the client device's hardware elements, aiming to perform communication or capturing context information.
Finally, the tools and applications developed by following the proposed specifications have helped to speed up the experiments performed to evaluate and verify several aspects of the proposal.

\section{References}

[1] J. Pascual, O. Sanjuán, J.M. Cueva, B.C. Pelayo, M. Álvarez, and A. González, Modeling architecture for collaborative virtual objects based on services, Journal of Network and Computer Applications 34(5) (2010), 1634-1647.

[2] J. Pascual, O. Sanjuán, B.C. Pelayo, J.M. Cueva, and P. Ordóñez, Standardization of Virtual Objects. Semantic Web Personalization and Context Awareness: Management of Personal Identities and Social Networking, M. Lytras, P. Ordóñez and E. Damiani, eds, IGI Global, 2011, pp. 7-21.

[3] J. Pascual, O. Sanjuán, B.C. Pelayo and J.M. Cueva, Virtual objects on the Internet of things, International Journal of Interactive Multimedia and Artificial Intelligence 1(4) (2011), 23-29.

[4] J. Pascual, R. González, O. Sanjuán, B.C. Pelayo, and J.M. Cueva, Extensible architecture for context-aware mobile web applications, Expert Systems with Applications 39(10) (2012), 9686-9694. 